\title{
Clinical profile of fungal sepsis in new born: a tertiary centre experience from Bangladesh
}

\begin{abstract}
Background: Candida infections are frequent and major causes of septicemia in neonatal intensive care units and are associated with high morbidity and mortality. Low birth weight preterm infants are especially vulnerable to these devastating infections.

Material and methods: A prospective observational study was done from May 2013 to June 2014 in SCABU (Special Care Baby Unit) \& ICU (Intensive Care Unit) of Dhaka Shishu (Children) Hospital, Dhaka. All neonates admitted with suspected clinical sepsis were analyzed in the study. Among which 30 culture positive candida cases were identified and included in this study. Outcome measures assessed was the incidence of candidemia in our NICU with clinical profiles and associated risk factors.

Results: Out of 30 newborns $18(60 \%)$ were preterms, $20 \%$ of study population were having a birth weight of $<1 \mathrm{~kg}, 23.3 \%$ with a birth weight of $1-1.5 \mathrm{~kg}$ and $23.3 \%$ with a birth weight of $1.5-2.5 \mathrm{~kg} .73 .4 \%$ of the study population were hospitalized for $>1$ week. In the study group $56.7 \%$ had feed intolerance, $53.3 \%$ needed ventilator support, $56.7 \%$ had temperature instability, $73.3 \%$ had thrombocytopenia $63.3 \%$ had apnea and $73.3 \%$ had jaundice. The overall survival was $63.3 \%$.

Conclusions Low birth weight, prematurity, use of broad spectrum antibiotics, mechanical ventilation and prolonged hospital stay were important risk factors associated with neonatal candidiasis in this study. Thrombocytopenia, feed intolerance, increased requirement for ventilator support, temperature instability, jaundice and apnea were significant clinical parameters noted in babies with culture proven neonatal candidiasis. The overall survival was $63.3 \%$ in the study group.
\end{abstract}

Keywords: Candida, Fungal sepsis, Fungal blood stream infection, Neonates, Preterm, Very low birth weight, Risk factors.
Volume 10 Issue 6 - 2020

Farhana Tasneem,' Mohammad Monir Hossain, ${ }^{2}$ Salahuddin Mahmud, ${ }^{3}$ Syed Shafi Ahmed ${ }^{4}$

'Assistant Professor, Department of Pediatrics, BIHS General Hospital, Diabetic Association of Bangladesh, Bangladesh ${ }^{2}$ Professor of Neonatal Intensive Care Unit, Bangladesh Institute of Child Health, Dhaka Shishu (Children) Hospital, Bangladesh ${ }^{3}$ Associate Professor, Department of Pediatric Gastroenterology, Hepatology \& Nutrition, Bangladesh Institute of Child Health, Dhaka Shishu (Children) Hospital, Bangladesh

${ }^{4}$ Professor \& Head, Department of Pediatric Gastroenterology, Hepatology \& Nutrition, Bangladesh Institute of Child Health, Dhaka Shishu (Children) Hospital, Bangladesh

Correspondence: Dr. Farhana Tasneem, Assistant Professor Department of Pediatrics, BIHS General Hospital, Diabetic Association of Bangladesh, Bangladesh, Email drftasneem@gmail.com

Received: November 25, 2020 | Published: December 28 2020

\section{Introduction}

Newborn survival is considerably improved by the advances in neonatal management. However, early $(<72$ hours) and late $(>72$ hours) onset systemic infections, both bacterial and fungal remain as an important cause of morbidity and mortality in these babies. Neonatal invasive candidiasis is a serious and common cause of late onset sepsis and has a high mortality (25 to $35 \%){ }^{2}$ Over the past 15 years, the incidence of such fungal infections has increased 11 fold. Preterm infants are predisposed to Candida infections because of immaturity of their immune system and invasive interventions. Vertical (from maternal vaginal infection) or nosocomial transmission of Candida are common. ${ }^{3,4}$ Candida infections are frequent and major causes of septicemia in neonatal ICUs, and are associated with high morbidity and mortality rates. The sources of candidiasis are mostly endogenous, and the frequency of the disease is influenced by the patient population and by various treatment regimens, antibiotics, and other supportive care procedures. ${ }^{5}$ Clinical presentation of candidemia resembles sepsis, hence its clinical diagnosis is difficult., Signs of fungal sepsis include thrombocytopenia, lethargy, glucose instability, increasing ventilation requirement and apnoea. End organ damage is more common and severe in systemic fungal infections and the kidneys, joint, brain, lung, eyes, liver, spleen and bones can be involved. ${ }^{8}$ Widespread infection despite negative culture is common. ${ }^{9}$

As most of the studies about the epidemiology and risk factors association of the blood stream infection due to candida species are retrospective, so we planned a prospective study to evaluate the epidemiology, risk factors and microbiological parameters associated with fungal sepsis in neonates as well as NICU patients.

\section{Material \& methods}

This prospective observational study was done from May 2013 to June 2014 in SCABU (Special Care Baby Unit) \& ICU (Intensive Care Unit) of Dhaka Shishu (Children) Hospital, Dhaka. From a total of 597 admitted cases with maternal risk factors for sepsis eg. Premature rupture of membrane or prolonged rupture of membrane for $>18$ hours, maternal intrapartum fever, urinary tract infection, foul smelling vaginal discharge or liquor and the newborn having clinical signs and symptoms of sepsis: hypo/hyperthermia, lethargy, apnoea, bradycardia, tachycardia, hypoperfusion, feeding intolerance, abdominal distension, tachypnea, respiratory distress were analyzed in the study. The pathological studies like $\mathrm{Hb} \%$, TLC \& DC of WBC, Platelet count along with blood film, CRP, RBS along with isolation $\&$ identification of the microbial isolates were done by sending blood culture in all cases. Among which 30 culture positive candida cases were identified and included in this study.

\section{Statistical analysis}

Statistical analysis was done using computer software SPSS (Statistical Package for Social Science) 16.0 version. Prevalence of organism was determined and expressed in percentage. 


\section{Results}

Out of 597 neonates who were suspected as clinical sepsis, fungal sepsis was found in $30(5.0 \%)$ cases. Among them 19 (63.3\%) were male and $11(36.7 \%)$ were female. Male to female ratio was 2:1 (Table $1)$.

Table I Gender distribution in the study group

\begin{tabular}{lll}
\hline Gender & Number $(\mathbf{N}=\mathbf{3 0})$ & Percentage $(\%)$ \\
\hline Male & 19 & 63.3 \\
Female & II & 36.7
\end{tabular}

The preterm neonates comprised $60.0 \%$ (Table 2).

Table 2 Gestational age

\begin{tabular}{lll}
\hline Gestational age & Number $(\mathbf{N}=\mathbf{3 0})$ & Percentage $(\%)$ \\
\hline$<32$ weeks & II & 36.7 \\
$32-36$ weeks & 7 & 23.3 \\
$>36$ weeks & 12 & 40 \\
\hline
\end{tabular}

Most of the neonates were low birth weight, $63.3 \%$ (Table 3 ).

Table 3 Body weight

\begin{tabular}{lll}
\hline Body weight & Number $(\mathbf{N}=\mathbf{3 0})$ & Percentage (\%) \\
\hline$<1 \mathrm{~kg}$ & 6 & 20 \\
$1-1.5 \mathrm{~kg}$ & 7 & 23.3 \\
$1.6-2.5 \mathrm{~kg}$ & 6 & 20 \\
$>2.5 \mathrm{~kg}$ & $\mathrm{II}$ & 36.7 \\
\hline
\end{tabular}

Out of 30 culture positive newborns admitted during the study period, majority of the babies had a hospital stay duration of more than one week. $22(73.4 \%)$ out of 30 babies had a prolonged hospital stay before developing candidial sepsis (Table 4).

Table 4 Duration of hospital stay

\begin{tabular}{lll}
$\begin{array}{l}\text { Duration of } \\
\text { hospital stay }\end{array}$ & Number $(\mathbf{N}=\mathbf{3 0})$ & Percentage (\%) \\
\hline$<1$ week & 8 & 26.6 \\
$>$ I week & 22 & 73.4 \\
\hline
\end{tabular}

$19(63.3 \%)$ out of 30 newborns had apnea during hospital stay. They had cessation of respiration for 20 seconds associated with bradycardia, cyanosis or both. Some had recurrent episodes of apnea. The remaining 11 babies did not have apnea during the hospital stay (Table 5).

Table 5 Presence of apnea

\begin{tabular}{lll}
\hline $\begin{array}{l}\text { Presence of } \\
\text { apnea }\end{array}$ & Number $(\mathbf{N}=\mathbf{3 0})$ & Percentage (\%) \\
\hline Yes & 19 & 63.3 \\
No & II & 36.7 \\
\hline
\end{tabular}

Feed intolerance was present in 17 (56.7\%) out of 30 babies. Most frequent features of feed intolerance were gastric residuals more than $50 \%$, vomiting, abdomen distention or visible bowel loops disrupting the enteral nutrition plan. Abdominal distention was assessed by measuring the abdominal girth (Table 6).
Table 6 Feed intolerance

\begin{tabular}{|c|c|c|}
\hline Feed intolerance & Number $(\mathbf{N}=30)$ & Percentage (\%) \\
\hline Yes & 17 & 56.7 \\
\hline \multirow{2}{*}{\multicolumn{3}{|c|}{$\begin{array}{l}\text { Jaundice was prevalent } \\
(73.3 \%) \text { had jaundice (Table } \\
\text { Table } 7 \text { Presence of jaundice }\end{array}$}} \\
\hline & & \\
\hline $\begin{array}{l}\text { Presence of } \\
\text { jaundice }\end{array}$ & Number $(\mathbf{N}=\mathbf{3 0})$ & Percentage (\%) \\
\hline Yes & 22 & 73.3 \\
\hline No & 8 & 26.7 \\
\hline
\end{tabular}

Temperature instability was present in $17(56.7 \%)$ out of 30 new borns. Temperature of babies was monitored throughout the hospital stay. Babies with temperature less than $36.5^{\circ} \mathrm{C}$ and $\geq 37.5^{\circ} \mathrm{C}$ were included as having temperature instability (Table 8 ).

Table 8 Temperature instability

\begin{tabular}{lll}
\hline $\begin{array}{l}\text { Temperature } \\
\text { instability }\end{array}$ & Number $(\mathbf{N}=\mathbf{3 0})$ & Percentage (\%) \\
\hline Yes & 17 & 56.7 \\
No & 13 & 43.3 \\
\hline
\end{tabular}

Thrombocytopenia was present in $22(73.3 \%)$ out of 30 babies. Thrombocytopenia was defined as platelet count less than 1.5 lakh. It was analyzed as a clinical parameter in babies with neonatal candidiasis (Table 9).

Table 9 Thrombocytopenia

\begin{tabular}{lll}
\hline Thrombocytopenia & Number $(\mathbf{N}=\mathbf{3 0})$ & Percentage $(\%)$ \\
\hline Yes & 22 & 73.3 \\
No & 8 & 26.7
\end{tabular}

Prolonged use of antibiotic comprises one third of candidemic babies ie. 10 babies (33.3\%) (Table 10).

Table 10 Antibiotic use

\begin{tabular}{lll}
\hline Duration & Number $(\mathbf{N}=\mathbf{3 0})$ & Percentage $(\%)$ \\
\hline$<7$ days & 3 & 10 \\
$7-14$ days & 5 & 16.7 \\
$>14$ days & 10 & 33.3 \\
Not used & 12 & 40
\end{tabular}

16 neonates $(53.3 \%)$ required ventilator support either for recurrent apnea, hypoxemia or poor perfusion (Table 11).

Table I I Ventilator support

\begin{tabular}{lll}
\hline Duration & Number $(\mathbf{N}=\mathbf{3 0})$ & Percentage $(\%)$ \\
\hline$<7$ days & 2 & 6.7 \\
$7-14$ days & 6 & 20 \\
$>14$ days & 8 & 26.6 \\
Not used & 14 & 46.7 \\
\hline
\end{tabular}

Out of 30 newborns with culture proven candidiasis, 19 survived $(63.3 \%)$ (Table 12). 
Table 12 Overall survival

\begin{tabular}{lll}
\hline Survival & Number $\mathbf{( N = 3 0 )}$ & Percentage (\%) \\
\hline Yes & 19 & 63.3 \\
No & 11 & 36.7
\end{tabular}

\section{Discussion}

Fungal sepsis is an important cause of morbidity \& mortality in sick newborn infants. In the present study, candida was isolated from $30 / 597(5.0 \%)$. This was higher than the study conducted by Celebi $\mathrm{S}$ et al. and Jinjian $\mathrm{Fu}$ et al. where the incidence was $1.1 \%{ }^{11,12}$ But opposite reflections was seen in Yunus et al. ${ }^{13}(9.2 \%)$, Pandita et al. ${ }^{1}$ seen $(13.8 \%)$, Agarwal et al. ${ }^{14}(13.6 \%)$ and Rani et al. ${ }^{15}(11 \%)$.

Sixty percent $(60.0 \%)$ of the babies were below 36 weeks of gestational age. Among them more than half belongs to $<32$ weeks group. But, James et al. ${ }^{5}$ found $97.5 \%$ of the babies below 36 weeks group and $45 \%$ of the study population were in 28-32 weeks group. Most $(63.3 \%)$ of the neonates positive for candidemia belongs to low birth weight group. This is in close agreement with many other reports. ${ }^{1,14}$

Twenty two (73.4\%) out of 30 babies, developed neonatal candidiasis and had a hospital stay of more than 1 week. Which is similar to James et al ${ }^{5}$ where it was $75 \%$. None of them had an indwelling central venous catheter.

Temperature instability was observed in $17(56.7 \%)$ out of 30 babies which is close to the finding of James et al. ${ }^{5} 52.5 \%$. Feed intolerance was present in 17 out of 30 babies $(56.7 \%)$. It corresponds to $58 \%$ in other study. ${ }^{5}$ Apnoea occurred in 19 out of 30 neonates $(63.3 \%)$ in the study group. This is higher than James et al. ${ }^{5} 50 \%$.

Thrombocytopenia can be specific marker of fungal sepsis in NICU. In our study 22 out of 30 babies ( $73.3 \%$ ) had thrombocytopenia. Which is comparable to Yunus et al. ${ }^{13} 66 / 83(80 \%)$ but lower than Guida et al. ${ }^{16}$ which reported nearly $85 \%$ incidence of thrombocytopenia in patients with invasive fungal sepsis. While Ariff et al. ${ }^{6}$ reported, $60 \%$ patients had low platelet count in their study.

In the present study, broad spectrum antibiotics were being administered to most of the neonates $(60 \%)$ and more than one third $(33.3 \%)$ of cases there was prolonged use of the antibiotics. They promote fungal overgrowth at the cost of normal bacterial flora and encourage translocation of yeast across the intact mucosa. The risk of candidemia is increased significantly with each class of antimicrobial used. Long term use of these broad-spectrum antibiotics create a negative pressure and favorable environment for Candida spp. to flourish. This proves the need of prophylactic antifungal to be used in a set up where continuous rise in the incidence of candidemia is seen.

More than half $(53.3 \%)$ of the babies needed ventilator support. Mechanical ventilation has well been described as a risk factor for the development of neonatal fungal blood stream infection. ${ }^{17}$ Out of 30 newborns with culture proven candidiasis, 19 survived (63.3\%). This result is similar to James et al. ${ }^{5}(60 \%)$ study.

\section{Conclusion}

In this study, low birth weight, prematurity, use of broad spectrum antibiotics, mechanical ventilation and prolonged hospital stay were important risk factors associated with neonatal candidiasis. Thrombocytopenia, feed intolerance, increased requirement for ventilator support, temperature instability, jaundice and apnea were significant clinical parameters noted in babies with culture proven neonatal candidiasis. The overall survival was reasonably good.

\section{Acknowledgments}

None.

\section{Conflicts of interest}

The authors do not declare any conflict of interest in relation to this article.

\section{Funding}

None.

\section{References}

1. Pandita N, Peshin C, Wasim S, et al. Profile of Fungal Septicaemia in aNew born at a Te rtiary Care Hospital in North India. Int J Contemp Pediatr. 2017;4(2): 455-459.

2. de Haan TR, Beckers L, de Jonge RC, Spanjaard L, et al. Neonatal gram negative and Candida sepsis survival and neurodevelopmental outcome at the corrected age of 24 months. PLoS One. 2013;8(3):e59214.

3. Steinbach WJ, Roilides E, Berman D, et al. Results from a prospective, international, epidemiologic study of invasive candidiasis in children and neonates. Pediatric Infect Dis J. 2012;31(12):1252-1257.

4. Goudjil S, Kongolo G, Dusol L, et al. (1-3)- $\beta-D-$ glucan levels in candidiasis infections in the critically ill neonate. $J$ Maternal-Fetal Neonat Medicine. 2013;26(1):44-48.

5. James M, Anuja JS, Ninan J. Clinical profile of neonatal candidiasis in new born nursery. Int J Contemp Pediatr. 2018; 5(2):334-337.

6. Ariff S, Saleem AF, Soofi SB, et al. Clinical spectrum and outcomes of neonatal candidiasis in a tertiary care hospital in Karachi, Pakistan. $J$ Infect Dev Ctries. 2011;5:216-223.

7. Zaoutis TE, Prasad PA, Localio AR, et al. Risk factors and predictors for candidemia in pediatric intensive care unit patients: Implications for prevention. Clin Infect Dis. 2010;51:38-45.

8. Benjamin DK, Ross K, McKinney RE, et al. When to suspect fungal infection in neonates: a clinical comparision of candida albicans and candida paraspilosis fungemia with coagulase -negative staphylococcal bacterimia. Paediatr. 2000:106:712-718.

9. Kler N, Garg P. Fungal sepsis. Bull Nat Neonatol Forum. 1999;13:1315 .

10. Oeser C, Lamagni T, Heath PT, et al. The epidemiology of neonatal and pediatric candidemia in England and Wales, 2000-2009. Pediatr Infect Dis J. 2013;32(3):222-226.

11. Celebi S, Hacimustafaoglu M, Koksal N, et al. Neonatal candidiasis: results of an 8 year study. Pediatr Int. 2012;54(3): 341-349.

12. Fu J, Ding Y, Wei B, et al. Epidemiology of Candida albicans and non-C. albicans of neonatal candidemia at a tertiary care hospital in western China. BMC Infect Dis. 2017;17(1):329.

13. Yunus M, Agarwal V, Tomer P, et al. Epidemiology, clinical spectrum and outcomes of fungal sepsis in neonates in neonatal intensive care unit: A prospective observational study. International Journal of Contemporary Medical Research. 2018;5(1):1-5.

14. Agarwal J, Bansal S, Malik GK, et al. Trends in neonatal septicemia: Emergence of non-albicans Candida. Indian Pediatr. 2004;41:712-715.

15. Rani R, Mohapatra NP, Mehta G, et al. Changing trends of Candida species in neonatal septicemia in a tertiary north Indian hospital. Indian J Med Microbiol. 2002; 20:42-44. 
16. Guida JD, Kunig AM, Leef KH, et al. Platelet Count and Sepsis in Very Low Birth Weight Neonates: Is There an Organism-Specific Response? Pediatrics. 2003;111:1411-1415.
17. Sardana V, Pandey A, Madan M, et al. Neonatal candidemia:a changing trend. Indian J Pathol Microbiol. 2012;55:132-133. 